\title{
Dietary supplementation with fish oil rich in $\omega-3$ polyunsaturated fatty acids in children with bronchial asthma
}

\author{
T. Nagakura*, S. Matsuda**, K. Shichijyo**, H. Sugimoto**, K. Hata***
}

\begin{abstract}
Dietary supplementation with fish oil rich in $\omega-3$ polyunsaturated fatty acids in children with bronchial asthma. T. Nagakura, S. Matsuda, K. Shichijyo, H. Sugimoto, K. Hata. (C) ERS Journals Ltd 2000.

ABSTRACT: $\omega$-3 Polyunsaturated fatty acids have anti-inflammatory effects in vitro, and high dietary levels are associated with a lower incidence of inflammatory diseases. However, only limited effects have been demonstrated in asthma. The effects of dietary supplementation with fish oil for 10 months in 29 children with bronchial asthma was investigated in a randomized controlled fashion.

In order to minimize the effects of environmental inhaled allergens and diet, this study was performed in a long-term treatment hospital. Subjects received fish oil capsules containing $84 \mathrm{mg}$ eicosapentaenoic acid (EPA) and $36 \mathrm{mg}$ docosahexaenoic acid (DHA) or control capsules containing $300 \mathrm{mg}$ olive oil. The daily dosages of EPA and DHA were 17.0-26.8 and 7.3-11.5 $\mathrm{mg} \cdot \mathrm{kg}$ body weight $^{-1}$, respectively.

Asthma symptom scores decreased and responsiveness to acetylcholine decreased in the fish oil group but not in the control group. In addition, plasma EPA levels increased significantly only in the fish oil group $(p<0.0088)$. No significant side-effects were observed.

The present results suggest that dietary supplementation with fish oil rich in the $\omega-3$ polyunsaturated fatty acids eicosapentaenoic acid and docosahexaenoic acid is beneficial for children with bronchial asthma in a strictly controlled environment in terms of inhalant allergens and diet.
\end{abstract}

Eur Respir J 2000; 16: 861-865.

*Dept of Paediatrics, Jikei University
School of Medicine, Tokyo, **Dept of
Paediatrics, National Higashi Saitama
Hospital, Saitama-ken, and ***Central
Research Centre, Nippon Suisan Kaisha
Ltd., Tokyo, Japan.

Correspondence: T. Nagakura, Yoga Allergy Clinic, Greenhouse No. 6-201, 4-11-17, Yoga, Setagaya-ku, Tokyo, 1580097 Tokyo, Japan. Fax: 81354914497

Keywords: Docosahexaenoic acid eicosapentaenoic acid

fish oil

polyunsaturated fatty acids

provocative concentration of acetylcholine causing a $20 \%$ fall in forced expiratory

volume in one second

Received: July 261999

Accepted after revision July 72000
Recent evidence suggests that inflammation is important in the pathogenesis of asthma [1]. Eicosapentaenoic acid (EPA) and docosahexaenoic acid (DHA) are $\omega$-3 polyunsaturated fatty acids that competitively inhibit the formation of leukotrienes and prostaglandins from arachidonic acids and $\omega-6$ fatty acids [2] and reduce the generation of cytokines from inflammatory cells [3]. Epidemiological studies in Inuit, Dutch [4], American [5], Australian [6] and Japanese populations [7] have shown that a high dietary intake of $\omega-3$ fatty acids or fish is associated with lower incidences of cardiovascular disease and inflammatory diseases such as asthma and type 1 diabetes mellitus. However, dietary supplementation with fish oil rich in these $\omega-3$ fatty acids has shown little effect on asthma symptoms. Fish oil significantly attenuates the allergeninduced late-phase asthmatic reaction but not the earlyphase reaction [8] and has no effect on seasonal hay fever or asthma in pollen-sensitive subjects [9].

Because these earlier trials were too short for an effect to be demonstrated (10 weeks [10], 6-14 weeks [11] and 6 months $[9,12])$, a 10-month study of the effects of fish oil on bronchial asthma in children was performed.

\section{Patients and methods}

The present study was a double-blind, controlled and randomized trial. The study protocol was approved by the ethics committee of the National Higashi Saitama Hospital, where the trial was performed. Informed consent was obtained from the patients and their parents.

\section{Study population}

The present study was performed in the Department of Paediatrics of the National Higashi Saitama Hospital, where $\sim 80$ children with asthma receive long-term treatment. The length of admission varies with the severity of the asthma but is generally one to several years. Children of elementary school and junior high school age are taught at the hospital by teachers sent by the Japanese Ministry of Education. Older children attend a high school near the hospital. Patients stay in the hospital ward $\sim 85 \%$ of the time. If their asthma improves and stabilizes, patients are allowed to visit their homes for the weekend. This setting is ideal for a long-term fish oil study because: 1) all patients receive the same foods, 2) the floor of the ward is vinyl, 3) bedding is washed once or twice a week, and 4) no toy stuffed animals are allowed. Therefore, food constituents and exposure to inhalant allergens were the same for all subjects during the study period.

\section{Subjects and protocol}

Twenty-nine children with asthma were included in the present study. The study was carried out between January 
1994 and March 1995. The first 2 months were considered the observation period and were followed by a 10-month administration period. Fish oil capsules or control (olive oil) capsules were administered between June 1994 and March 1995 (10 months). Blood samples were taken before the trial and at 1, 5, 7 and 10 months after the start of administration. Plasma was collected in sealed nitrogenfilled test tubes and stored at $-40^{\circ} \mathrm{C}$ until assay. The acetylcholine inhalation test was performed every other month.

\section{Randomization}

Children were randomized to receive either fish oil capsules (fish oil group) or control capsules (control group). The randomization was stratified with a restricted randomization and a block size of four. The fish oil capsules (300 mg) contained $84 \mathrm{mg}$ EPA and $36 \mathrm{mg}$ DHA (Nippon Suisan Kaisha Ltd., Tokyo, Japan), and the control capsules contained $300 \mathrm{mg}$ olive oil (Nippon Suisan Kaisha Ltd.), which is visually indistinguishable from fish oil. Since the body weight of the children ranged $18.8-59.2 \mathrm{~kg}$ (4-17 yrs), children weighing 18.8-24.2 kg took 6 capsules day (two capsules three times daily; 2-2-2), $24.8-32.6 \mathrm{~kg} 8$ capsules.day ${ }^{-1}(3-2-3), 34.0-41.4 \mathrm{~kg}$ 10 capsules $^{-d_{a y}{ }^{-1}}(3-3-4)$ and $45.3-59.2 \mathrm{~kg} 12$ capsules. day $^{-1}$ (4-4-4). Therefore, the daily dosages of EPA and DHA were 17.0-26.8 and 7.3-11.5 mg. kg body weight ${ }^{-1}$, respectively.

\section{Acetylcholine inhalation test}

Acetylcholine was dissolved in physiological saline and administered via a Nissho nebulizer (Nissho K.K., Tokyo, Japan) using compressed air at a flow rate of $5 \mathrm{~L} \cdot \mathrm{min}^{-1}$. The provocative concentration of acetylcholine causing a $20 \%$ fall in forced expiratory volume in one second (FEV1) [13] was determined by getting the subjects to inhale a doubling range of acetylcholine concentrations (78$10,000 \mu \mathrm{g} \cdot \mathrm{mL}^{-1}$ ) during tidal breathing for $2 \mathrm{~min}$ at $15-$ min intervals. Medications were withheld for $\geq 24 \mathrm{~h}$ before the test. The acetylcholine inhalation test was performed every other month.

\section{Asthma scoring}

A mild asthma attack (score 1) was defined as wheezing audible by stethoscope but no dyspnoea, a moderate attack (score 2) as the use of accessory respiratory muscles and slight cyanosis in room air, and a severe attack (score 3 ) as cyanosis in $40 \%$ oxygen and decreased or absent inspiratory breath sounds due to poor air exchange. Children were observed $24 \mathrm{~h} \cdot$ day $^{-1}$ by paediatricians or nurses. The highest score in each 6-h period (09:00-15:00, 15:0021:00, 21:00-03:00 and 03:00-09:00 h) was regarded as the score for that period. The total of the four scores in $24 \mathrm{~h}$ was recorded as the asthma score for 1 day.

\section{Eicosapentaenoic and docosahexaenoic acid assays}

Levels of EPA and DHA were measured using previously described modified methods [13-16]. Briefly, lipids were extracted from plasma with chloroform/methanol. The extract was purified by means of preparative thin-layer chromatography. The phospholipid fraction was subjected to transesterification by boron trifluoride diethyl etherate with tricosanoic acids as internal standards. The resulting methyl esters were analysed by means of gas chromatography. The fatty acid composition of the total lipids was evaluated using the above procedure but without preparative thin-layer chromatography.

\section{Statistical analysis}

All patients were included in the efficacy (intention-totreat) analysis. The differences between the data obtained before administration and those obtained each month after the start of administration were calculated. These differences were used for further analysis. The Wilcoxon signed-rank test was used to compare the data obtained each month before and after administration within and between groups. A $p$-value of $p<0.05$ was regarded as significant.

Analysis of variance of asthma score and acetylcholine threshold was performed in the two groups.

\section{Results}

Thirty children with asthma were registered for the study. One child dropped out because of inability to swallow the capsules at the start of administration. Thus 29 children were finally enrolled in the study. There were no significant differences between the fish oil group and the control group in age, sex, or medications (table 1). Acute asthma attacks were treated with inhaled $\beta_{2}$-agonist every 3-4 $\mathrm{h}$ and with intravenous theophylline with or without hydrocortisone. The two groups differed significantly in the amount of medication used for acute asthma attacks during the study.

Table 1. - Baseline characteristics

\begin{tabular}{lcc}
\hline & Fish oil group & Control group \\
\hline Subjects $\mathrm{n}$ & 15 & 14 \\
Age yrs & $10.2 \pm 2.5$ & $11.9 \pm 3.1$ \\
Male:female & $8: 7$ & $7: 7$ \\
FEV1 \% pred & $84.9 \pm 7.3$ & $82.9 \pm 9.5$ \\
IgE IU·mL & $823 \pm 121$ & $620 \pm 95$ \\
Asthma duration yrs & $9.2 \pm 3.2$ & $11.1 \pm 4.9$ \\
Medication (daily doses) & & \\
Theophylline mg & $362 \pm 123$ & $405 \pm 96$ \\
Salbutamol mg & $1.1 \pm 0.1$ & $0.8 \pm 0.2$ \\
DSCG mg & $42 \pm 18$ & $48 \pm 23$ \\
BDP $(\mathrm{n}=3) \mu \mathrm{g}$ & $100,200,200$ & $100,150,300$ \\
\hline
\end{tabular}

Data are mean $\pm \mathrm{SD}$ at study entry. $\mathrm{FEV} 1$ : forced expiratory volume in one second; IgE: immunoglobulin E; IU: international units; DSCG: disodium cromoglycate; BDP: beclomethasone dipropionate. 
Table 2. - Plasma eicosapentaenoic acid (EPA) level in the children included in the study before and at various times after oil administration

\begin{tabular}{|c|c|c|c|c|}
\hline $\begin{array}{l}\text { Time after administration } \\
\text { months }\end{array}$ & $\begin{array}{l}\text { Subjects } \\
\mathrm{n}\end{array}$ & $\begin{array}{l}\text { Plasma EPA } \\
\mu \mathrm{g} \cdot \mathrm{mL}^{-1}\end{array}$ & $\underset{\mu \mathrm{g} \text { lasma EPA }}{\mu \mathrm{mL}^{-1}}$ & p-value \\
\hline \multicolumn{5}{|l|}{ Fish oil group } \\
\hline Before & 15 & $24.19 \pm 3.30$ & - & - \\
\hline 2 & 15 & $45.81 \pm 3.84$ & $-21.61 \pm 3.58$ & 0.0001 \\
\hline 4 & 14 & $45.80 \pm 3.06$ & $-21.61 \pm 4.05$ & 0.0001 \\
\hline 7 & 13 & $49.06 \pm 4.59$ & $-24.87 \pm 5.40$ & 0.0004 \\
\hline 10 & 11 & $55.76 \pm 8.34$ & $-29.90 \pm 9.41$ & 0.0088 \\
\hline \multicolumn{5}{|l|}{ Control group } \\
\hline Before & 14 & $20.43 \pm 2.95$ & - & - \\
\hline 2 & 14 & $25.07 \pm 2.86$ & $-4.64 \pm 9.68$ & 0.0958 \\
\hline 4 & 13 & $25.43 \pm 3.70$ & $-4.13 \pm 16.61$ & 0.3874 \\
\hline 7 & 13 & $22.34 \pm 3.71$ & $-1.04 \pm 9.45$ & 0.6989 \\
\hline 10 & 12 & $34.63 \pm 10.70$ & $-13.30 \pm 36.87$ & 0.2374 \\
\hline
\end{tabular}

Data are presented as mean \pm SEM. $\Delta$ : difference (before-after).

No side-effects, such as prolonged epistaxis, bleeding tendency or menstrual problems, were reported during the study in the fish oil group.

In the fish oil group, 15 children began the 10-month study and 11 completed it. In the control group, 14 children began the study and 12 completed it. Two patients whose asthma improved were discharged after 6 months at the request of their parents.

The two groups did not differ significantly in asthma score, acetylcholine threshold or plasma EPA levels in the 2 months before administration of oil capsules. The baseline FEV1 during the premedication (control) period did not differ significantly between the fish oil $(85.5 \pm 6.5 \%$ of the predicted value (mean $\pm \mathrm{SEM}$ ), and control groups $(82.4 \pm 8.5)$.
In the fish oil group, EPA levels 2, 4, 7 and 10 months after the start of administration were significantly higher $(\mathrm{p}<0.01)$ than during the control period, whereas levels in the control group showed no significant change (table 2). Serum EPA levels in the fish oil group were significantly higher than those in the control group $2(\mathrm{p}=0.008), 4$ $(p=0.01), 7 \quad(p=0.001)$ and 10 months $(p=0.001)$ after the start of administration. The analysis of variance $\mathrm{p}$ value was 0.0001 in the fish oil and 0.330 in the control group.

Asthma scores were significantly lower than at baseline in the fish oil group in the 6th $(\mathrm{p}=0.005), 7$ th $(\mathrm{p}=0.014)$, 8th $(p=0.007), 9$ th $(p=0.032)$ and 10th months after the start of administration $(\mathrm{p}=0.01)$ and were also lower in the control group in the 7 th and 9 th months (table 3 ). In

Table 3. - Asthma scores of the children included in the study before and at various times after oil administration

\begin{tabular}{|c|c|c|c|c|}
\hline $\begin{array}{l}\text { Time after administration } \\
\text { months }\end{array}$ & $\begin{array}{c}\text { Subjects } \\
\mathrm{n}\end{array}$ & $\begin{array}{l}\text { Asthma score } \\
\text { score } \text { month }^{-1}\end{array}$ & $\begin{array}{l}\Delta \text { Asthma score } \\
\text { score } \cdot \text { month }^{-1}\end{array}$ & p-value \\
\hline \multicolumn{5}{|l|}{ Fish oil group } \\
\hline Before & 15 & $21.48 \pm 5.91$ & - & - \\
\hline 1 & 15 & $16.47 \pm 7.17$ & $5.01 \pm 4.72$ & 0.055 \\
\hline 2 & 14 & $20.29 \pm 9.49$ & $0.50 \pm 4.90$ & 0.217 \\
\hline 3 & 14 & $20.71 \pm 6.34$ & $0.07 \pm 3.86$ & 0.808 \\
\hline 4 & 14 & $14.43 \pm 7.18$ & $6.36 \pm 6.07$ & 0.173 \\
\hline 5 & 14 & $14.43 \pm 5.73$ & $6.36 \pm 3.58$ & 0.081 \\
\hline 6 & 14 & $9.43 \pm 4.65$ & $11.36 \pm 5.05$ & 0.005 \\
\hline 7 & 14 & $5.50 \pm 2.26$ & $15.29 \pm 5.88$ & 0.014 \\
\hline 8 & 11 & $11.00 \pm 5.89$ & $15.15 \pm 6.39$ & 0.007 \\
\hline 9 & 11 & $12.36 \pm 6.14$ & $13.78 \pm 6.13$ & 0.032 \\
\hline 10 & 11 & $6.09 \pm 2.45$ & $20.05 \pm 7.24$ & 0.010 \\
\hline \multicolumn{5}{|l|}{ Control group } \\
\hline Before & 14 & $13.66 \pm 4.34$ & - & - \\
\hline 1 & 14 & $12.93 \pm 6.31$ & $0.73 \pm 3.09$ & 0.745 \\
\hline 2 & 14 & $18.14 \pm 6.99$ & $-4.49 \pm 3.08$ & 0.314 \\
\hline 3 & 14 & $18.36 \pm 5.91$ & $-4.70 \pm 4.41$ & 0.552 \\
\hline 4 & 13 & $19.92 \pm 7.83$ & $-5.80 \pm 4.07$ & 0.414 \\
\hline 5 & 13 & $16.23 \pm 4.85$ & $-2.11 \pm 2.54$ & 0.552 \\
\hline 6 & 13 & $8.69 \pm 5.10$ & $5.43 \pm 3.86$ & 0.060 \\
\hline 7 & 13 & $9.23 \pm 3.56$ & $4.89 \pm 2.29$ & 0.005 \\
\hline 8 & 12 & $20.33 \pm 3.75$ & $-5.55 \pm 5.01$ & 0.267 \\
\hline 9 & 12 & $7.58 \pm 3.36$ & $7.20 \pm 2.07$ & 0.002 \\
\hline 10 & 12 & $13.67 \pm 4.88$ & $1.12 \pm 5.36$ & 0.569 \\
\hline
\end{tabular}

Data are presented as mean \pm SEM. $\Delta$ : difference (before-after). 
Table 4. - Acetylcholine responsiveness in the children included in the study before and at various times after oil administration

\begin{tabular}{|c|c|c|c|c|}
\hline $\begin{array}{l}\text { Time after administration } \\
\text { months }\end{array}$ & $\begin{array}{l}\text { Subjects } \\
\mathrm{n}\end{array}$ & $\begin{array}{c}\mathrm{PC} 20 \\
\mu \mathrm{g} \cdot \mathrm{mL}^{-1}\end{array}$ & $\begin{aligned} \Delta \mathrm{PC} 20 \\
\mu \mathrm{g} \cdot \mathrm{mL}^{-1}\end{aligned}$ & p-value \\
\hline \multicolumn{5}{|l|}{ Fish oil group } \\
\hline Before & 15 & $979.46 \pm 510.40$ & - & - \\
\hline 2 & 14 & $820.36 \pm 336.75$ & $159.11 \pm 184.97$ & 0.8750 \\
\hline 4 & 14 & $1372.86 \pm 689.67$ & $-393.39 \pm 211.05$ & 0.1133 \\
\hline 6 & 14 & $1361.71 \pm 685.08$ & $-382.25 \pm 190.58$ & 0.0313 \\
\hline 8 & 12 & $2127.46 \pm 757.14$ & $-1168.80 \pm 363.09$ & 0.0005 \\
\hline 10 & 11 & $1846.73 \pm 873.92$ & $-855.82 \pm 215.88$ & 0.0010 \\
\hline \multicolumn{5}{|l|}{ Control group } \\
\hline Before & 14 & $1266.89 \pm 677.62$ & - & - \\
\hline 2 & 14 & $569.43 \pm 155.02$ & $697.46 \pm 530.16$ & 0.0469 \\
\hline 4 & 13 & $468.93 \pm 76.80$ & $797.96 \pm 618.75$ & 0.0469 \\
\hline 6 & 13 & $1250.23 \pm 732.85$ & $66.04 \pm 113.88$ & 0.3867 \\
\hline 8 & 13 & $1502.46 \pm 723.63$ & $-186.19 \pm 194.50$ & 0.9766 \\
\hline 10 & 12 & $1190.00 \pm 386.24$ & $175.88 \pm 485.78$ & 0.9219 \\
\hline
\end{tabular}

Data are presented as mean \pm SEM. $\mathrm{PC} 20$ : provocative concentration of acetylcholine causing a $20 \%$ fall in forced expiratory volume in one second; $\Delta$ : difference (before-after).

the analysis of the difference between the two groups, the p-value for each month was as follows: 0.315 (1st month), 0.098 (2nd month), 0.696 (3rd month), 0.139 (4th month), 0.094 (5th month), 0.827 (6th month), 0.369 (7th month), 0.021 (8th month), 0.829 (9th month) and 0.102 (10th month). The analysis of variance p-value was 0.034 in the fish oil group and 0.052 in the control group.

Threshold concentrations in the acetylcholine inhalation test were significantly lower in the fish oil group in the 6th $(p=0.0313), 8$ th $(p=0.0005)$ and 10th months after the start of administration $(\mathrm{p}=0.0010)$ and in the control group in the $2 \mathrm{nd}(\mathrm{p}=0.0469)$ and 4th months $(\mathrm{p}=0.0469)$ (table 4). The increase in the acetylcholine threshold was greater in the fish oil group than in the control group in the 2nd $(\mathrm{p}=0.875), 4$ th $(\mathrm{p}=0.113)$, 6th $(\mathrm{p}=0.031), 8$ th $(\mathrm{p}=0.001)$ and 10th months $(\mathrm{p}=0.001)$. The analysis of variance $\mathrm{p}$ value was 0.0002 in the fish oil group and 0.145 in the control group.

\section{Discussion}

The present study shows that dietary supplementation with fish oil rich in the $\omega-3$ polyunsaturated fatty acids EPA and DHA for 10 months decreases asthma scores and increases acetylcholine thresholds in children with bronchial asthma. It should be emphasized that these results were obtained in a strictly controlled environment in which food constituents and exposure to inhalant allergens were the same for all subjects throughout the 10-month study. Furthermore, the daily dose of medication was not changed during the study.

In previous studies, administration of fish oil prevented only allergen-induced late asthmatic reactions and had no effect on immediate reactions [8]. Indeed, several studies have even found that fish oil has no effect on asthma symptoms. However, unlike the present study, these previous studies were performed in outpatients [8-12].

A single meal rich in $\omega-6$ polyunsaturated fatty acids effectively raises the $\omega-6 / \omega-3$ polyunsaturated fatty acids ratio in serum, suggesting that, in the present study, the meals prepared by the hospital nutritionist were essential to maintaining this ratio over a certain period. In addition, levels of such inhalant allergens as Dermatophagoides antigen 1 vary from home to home. However, because the subjects of the present study spent $\sim 85 \%$ of the study period in the hospital, the degree of exposure to inhalant allergens was well controlled.

The mean plasma level of EPA in the fish oil group at the end of the study, $56 \mu \mathrm{g} \cdot \mathrm{mL}^{-1}$, was more than twice that at baseline. This did not result in increased bleeding tendency during the study. The optimal dose of $\omega-3$ polyunsaturated fatty acids is still to be determined. The fish oil administered in the present study also contained DHA, which also has anti-inflammatory properties. Therefore, which $\omega-3$ polyunsaturated fatty acids are beneficial in asthma could not be determined in this study.

Acetylcholine responsiveness decreased significantly in the fish oil group but not in the control group. FEV1 measured once a month throughout the study did not show any significant changes. These data suggest that supplementation with fish oil for $1 \mathrm{yr}$ improved airway inflammation but not airway calibre (FEV1 data not shown).

The present study was performed between 1994 and 1995, when inhaled steroids were only just beginning to become common in the treatment of childhood asthma in Japan. The authors now use beclomethasone and fluticasone in childhood asthma, if necessary. Therefore, it was not surprising that inhaled steroids were rarely used in children whose asthmatic symptoms were of a severe nature in the study.

EPA competitively inhibits the formation of leukotrienes from arachidonic acids and $\omega-6$ fatty acids [2] and reduces the generation of cytokines from inflammatory cells [3]. It has previously been found that EPA inhibits the immunoglobulin E-induced release from cultured human mast cells of prostaglandin $\mathrm{D}_{2}$ but not of histamine $[16,17]$. Histamine is an important preformed mediator of immediate-type hypersensitivity. The inability of EPA to inhibit the release of histamine from mast cells may explain why treatment with EPA blocked the late response to inhaled allergens but not the immediate response in patients with asthma [8]. 
After the Second World War, the greatest changes in the Japanese diet, particularly in that of younger persons, were an increase in foods rich in $\omega-6$ polyunsaturated fatty acids and a decrease in foods, such as fish, containing $\omega-3$ polyunsaturated fatty acids [7]. A recent epidemiological study found a lower prevalence of asthma in Japanese school children who consumed more fish. Japanese children with atopy have low serum levels of $\omega-3$ polyunsaturated fatty acids [18]. A low intake of foods containing $\omega-3$ or an increased ratio of $\omega-6 / \omega-3$ polyunsaturated free fatty acid in the diet may have contributed to the recent increased prevalence of childhood asthma in Japan.

Acknowledgements. The authors would like to thank H. Sasahara for performing statistical analysis.

\section{References}

1. Bousquet J, Chanez P, Campbell AM, Vignola AM, Godard P. Cellular inflammation in asthma. Clin Exp Allergy 1995; 25: 39-42.

2. Lee TH, Hoover RL, Williams JD, et al. Effect of dietary enrichment with eicosapentaenoic and docosahexaenoic acids on in vitro neutrophil and monocyte leukotriene generation and neutrophil function. $N$ Engl J Med 1985; 312: 1217-1224.

3. Endres S, Ghorbani R, Kelley VE, et al. The effect of dietary supplementation with n-3 polyunsaturated fatty acids on the synthesis of interleukin- 1 and tumor necrosis factor by mononuclear cells. N Engl J Med 1989; 320: 265-271.

4. Kromann N, Green A. Epidemiological studies in the Upernavik district, Greenland. Incidence of some chronic diseases 1950-1974. Acta Med Scand 1980; 208: 401406.

5. Schwartz J, Weiss ST. The relationship of dietary fish oil intake to level of pulmonary function in the first National Health and Nutrition Survey. Eur Respir J 1994; 7: 18211824.

6. Peat JK, Salome CM, Woolcock AJ. Factors associated with bronchial hyperresponsiveness in Australian adults and children. Eur Respir J 1992; 5: 921-929.
7. Satomi H, Minowa M, Hatano S, Nagakura T, Iikura Y. An epidemiological study of the preventive effect of dietary fish on the bronchial asthma. Bull Inst Public Health 1994; 43: 305-314.

8. Arm JP, Horton CE, Spur BW, Mencia-Huerta J-M, Lee $\mathrm{TH}$. The effects of dietary supplementation with fish oil lipids on the airways response to inhaled allergen in bronchial asthma. Am Rev Respir Dis 1989; 139: 13951400.

9. Thien FCK, Mencia-Huerta J-M, Lee TH. Dietary fish oil effects on seasonal hay fever and asthma in pollensensitive subjects. Am Rev Respir Dis 1993; 147: 11381143.

10. Arm JP, Horton CE, Mencia-Huerta J-M, et al. Effect of dietary supplementation with fish oil lipids on mild asthma. Thorax 1988; 43: 84-92.

11. Kirsch CM, Payan DG, Wong MYS, et al. Effect of eicosapentaenoic acid in asthma. Clin Allergy 1988; 18: 177-187.

12. Hodge L, Salome CM, Hughes JM, et al. Effects of dietary intake of omega- 3 and omega- 6 fatty acids on severity of asthma in children. Eur Respir $J$ 1997; 11: 361-365.

13. Cockcroft DW, Berscheid BA. Measurement of responsiveness to inhaled histamine: comparison of FEV1 and SGaw. Ann Allergy 1983; 51: 374-377.

14. Benner KG, Sasaki A, Gowen DR, Weaver A, Connor WE. The differential effect of eicosapentaenoic acid and oleic acid on lipid synthesis and VLDL secretion in rabbit hepatocytes. Lipids 1990; 25: 534-540.

15. Ashes JR, Siebert BD, Gulati SK, Cuthbertson AZ, Scott TW. Incorporation of $n-3$ fatty acids of fish oil into tissue and serum lipids of ruminants. Lipids 1992; 27: 629-631.

16. Marangoni F, Angeli MT, Colli S, et al. Changes of n-3 and $n-6$ fatty acids in plasma and circulating cells of normal subjects, after prolonged administration of 20:5 (EPA) and 22:6 (DHA) ethyl esters and prolonged washout. Biochim Biophys Acta 1993; 1210: 55-62.

17. Obata T, Nagakura T, Masaki T, Maekawa K, Yamashita K. Eicosapentaenoic acid inhibits prostaglandin $\mathrm{D}_{2}$ by inhibition of cyclooxygenase-2 in cultured human mast cells. Clin Exp Allergy 1999; 29: 1129-1135.

18. Sakai K, Ueno K, Ogawa Y, Okuyama H. Fatty acid compositions of plasma lipids in young atopic patients. Chem Pharm Bull 1986; 345: 2944-2949. 